\title{
Tres lecturas de Palma
}

Por Pedro Díaz Ortíz 
Decano de la Facultad de Humanidades y Lenguas Modernas de la Universidad Ricardo Palma. Director de la Serie "Letras Francesas" y de la Revista de la Facultad de Humanidades y Lenguas Modernas. 
En torno a la obra de Ricardo Palma, y en especial a las Tradiciones Peruanas, existe una serie de interpretaciones o lecturas, entre ellas: las de José de la Riva Agüero y Víctor Andrés Belaúnde; la de Manuel González Prada; y las de Víctor Raúl Haya de la Torre y José Carlos Mariátegui. Estas lecturas de Palma son, sin duda, las más importantes, no solo porque abordan una obra literaria desde puntos de vista completamente opuestos, sino también porque en ellas está presente la discusión ideológica respecto a nuestro ser y destino nacionales.

\section{Lectura de José de la Riva Agüero y Víctor Andrés Belaúnde}

Raúl Porras Barrenechea en el prólogo a Paisajes Peruanos, una de las obras fundamentales de José de la Riva Agüero, dice: "José de la Riva Agüero y Osma (1884-1944) es una de las más altas y representativas figuras del historicismo peruano del siglo XX y nuestro más auténtico humanista. Surgido de una vieja estirpe limeña, descendiente de los conquistadores de la isla del Gallo y de los fundadores de Lima, bisnieto del primer Presidente " republicano del Perú, desposeído por Bolívar, era, consustancialmente, un hombre de casta y de élite."

Si bien en las obras juveniles de Riva Agüero - como observa Porras-existe un denostamiento de la época colonial, incluso en

I De la Riva Agüero, José. Paisajes Peruanos, Prólogo de Raúl Porras Barrenechea, Ed. Peisa, Lima, 1974, p. 5. 
ellas subyacen los rasgos culturales del "espíritu de Riva Agüero, aristocrático y tradicionalista por instinto." ${ }^{2}$ Riva Agüero es, en este sentido, un representante de la clase dominante y, como tal, su visión de la historia y literatura peruana está teñida de una ideología hispanista y conservadora. Tal es lo que podemos observar en algunas afirmaciones de Riva Agüero sobre Ricardo Palma, la cultura y la literatura peruanas en su ensayo Carácter de la Literatura del Perú Independiente:

"Palma — dice- es el tipo de criollo culto, literario. Es muy raro este concierto del criollismo y la cultura. Los que entre nosotros se han dedicado a la descripción de las costumbres tradicionales y populares, han caído en la vulgaridad, en el mal tono, y en una jerga abigarrada y plebeya. Podemos comprobarlo con el ejemplo de don José Joaquín Larriva y, sobre todo, con el de Segura: 'Sus sales gruesas, a lo Plauto' como dijo Juan de Arona, su lenguaje a veces grotesco, su carencia de tacto y de elegancia, hacen que hoy tengamos casi olvidado a Segura y que no se le estudie sino en calidad de documento histórico, de antigüedad curiosa. Había en él dotes muy estimables de observador y de poeta cómico, pero para aprovecharlas debidamente le faltaron pulimiento y educación de gusto. Ricardo Palma es un Segura depurado y ennoblecido." 3

El análisis de este párrafo revela claramente el sentido de clase de José de la Riva Agüero. En primer lugar, la asociación "culto y literario" implica una utilización del adjetivo literario en el sentido aristocrático y restrictivo del término literatura: cultura y saber del hombre de letras, del letrado, en oposición al sermovulgaris. De ahí el sentido de la siguiente frase: "Es muy

2 De la Riva Agüero, José. Ob. Cit. p. 8.

3 De la Riva Agüero, José. Obras Completas, Tomo I, Carácter de la Literatura del Perú Independiente, Ed. Instituto Riva Agüero, Lima, 1962, p. 176. 
raro este concierto del criollismo y la cultura". No olvidemos, al respecto, la categoría de "ciudadano" de segundo orden que tenía el criollo en la Colonia, y que siguió teniendo en la República. Después de todo, la República no fue sino un cambio de godos o chapetones por españoles nacidos en América, régimen bajo el cual el criollo, el indio y el negro eran despreciados y explotados por "la argolla" como dice el mismo Ricardo Palma, refiriéndose a la casta dirigente ${ }^{4}$.

4 Ricardo Palma denomina argolla al grupo civilista, heredero y continuador de la casta de los conquistadores y encomenderos (señores de horca, cuchillo, pendón y caldera). Contra la argolla, Palma emplea los epítetos más duros. Y así la llama sucesivamente: la infame argolla (Palma, Ricardo. Cartas a Piérola, Ed. Milla Batres, Lima, 1979, p. 75); el nido de sierpes que se llama la argolla, p. 81; esa boa constrictora que se llama argolla, p. 63; A los alacranes se les arranca el aguijón para que no piquen, y alacranes muy ponzoñosos son los civilistas, p. 68. Lo primero es tener patria, y eso no lo tendremos mientras el pabellón chileno flamee en el litoral y no se haya hundido el civilismo en lo más profundo del invierno, p. 89.

Las Cartas a Piérola, así como su producción periodística, son los escritos menos conocidos de Palma. Sin embargo, ellos aportan datos fundamentales para comprender mejor su condición de escritor crítico de nuestra sociedad. Palma no es, como se suele pensar a veces, un escritor puro. Su obra, al contrario, está ligada a los grandes problemas sociales y políticos de su época, tal como puede apreciarse en Cartas a Piérola.

De otro lado, en Crónicas de la Guerra con Chile -obra de Palma de última aparición- aparece asimismo esta constante de su crítica implacable contra la argolla: Casi todos los representantes del aciago partido de la argolla, partido que fue el que con la caprichosa ley de expropiación de salitreras provocó la guerra con Chile, p. 22; (el) civilismo, autor exclusivo da la guerra y de todas las desventuras del Perú, p. 125; Para los hombres del civilismo, la cuestión interna, sus ambiciones, lucros y miserias, valen más que la liberación del país invadido por los extranjeros, p. 149.

En Crónicas de la Guerra con Chile, Palma desmitifica también el rol de los Estados Unidos como probable mediador en el conflicto con Chile y dice: "Lo que soy yo, Señor Director, no me forjo ilusiones. Nada de bueno espero de los Estados Unidos, que han sido los creadores exclusivos de la anarquía y de las pésimas condiciones en que hoy se encuentra el Perú. Tuvimos la inocentada de creer en la farándula y en las promesas de Mr. Hurlbut, a quien Dios perdone todo el mal que hizo a esta patria, y estamos divertidos en regla. Si algo le hubiera interesado a la Gran República la suerte de este infortunado país, su política habría sido leal, franca y altiva, y su diplomacia no habría sido diplomacia de callejón y encrucijada" (p. 170).

Y más adelante agrega: "De la amistad y cariño que los Estados Unidos profesan a las Repúblicas latinas puede decirse con el refrán iQué amigos tienes, Benito! iTe ven colgado y te aprietan el cordelito! (P. 170) 
De otro lado, la utilización de palabras y expresiones como vulgaridad, mal tono, jerga abigarrada y plebeya, lenguaje grotesco, carencia de tacto y elegancia, falta de pulimiento y educación de gusto, revelan menosprecio y desdén por las clases populares, su lengua y su cultura.

El criollismo es para Riva Agüero el sermovulgaris, salvo cuando el criollo asciende a culto, y se depura y ennoblece. En este contexto, se explica mejor el sentido de la frase final en el párrafo citado: "Ricardo Palma es un Segura depurado y ennoblecido".

Pero si este es su punto de vista acerca del criollo, el concepto que tiene de la sierra y de los indios es aún más revelador respecto a su visión hispanista de la realidad peruana: “ (...) parece que aquella naturaleza — dice refiriéndose a la sierra- no dejara otra Impresión que la del dolor resignado, y que sus habitantes, tímidos y silenciosos, no tuvieron otros sentimientos que la servil humildad y la desconfianza. No hay que engañarse: allí palpita secreta y pérfidamente una hostilidad recelosa y siniestra. El indio es rencoroso; aborrece al blanco y al mestizo con toda su alma; procura engañarles y perderles; si no les declara guerra franca es por cobardía. En él, como en todos los esclavos, fermentan odios mortales e inextinguibles. (...) Mucho costó desarraigar la idolatría y aún persisten en las supersticiones sus huellas."

En Riva Agüero, representante de la aristocracia intelectual, pervive el espíritu de los conquistadores y encomenderos. Al respecto, Ricardo Palma en su tradición Hermosa entre las Hermosas desmitifica a los conquistadores y sus descendientes:

Tanto las Cartas a Piérola como las Crónicas de la Guerra con Chile son la evidencia de un Palma al que hasta ahora todavía no se conoce en su verdadera dimensión. En su dimensión de escritor crítico y desmitificador de la realidad nacional y de sus lacras.

5 De la Riva Agüero, José. Obras Completas, Ob. Cit. pp. 189-190. 
Cuando afianzada ya la conquista, —dice Palma- se vieron los camaradas del marqués convertidos de aventureros en señores de horca, cuchillo, pendón y caldera, que no otra cosa fueron por más dibujos con que la historia se empeñe en dorarnos la píldora."

La historia y la literatura fueron, durante mucho tiempo, el patrimonio de la clase dirigente de nuestro país; por ende, su concepción hispanista e idealista de obras como las Tradiciones Peruanas en donde no supieron - o no quisieron- leer lo más auténtico e importante: es decir, la desmitificación de nuestra realidad, y se limitaron a destacar lo anecdótico y superficial. Pensaron y quisieron - en cierto sentido, lo lograron- hacer de Palma tan solo un evocador y creador de la imagen arcádica de la Colonia. De ahí que la ideología de escritores como José de la Riva Agüero y Víctor Andrés Belaúnde coinciden en su apreciación de la obra de Ricardo Palma en juicios como: las tradiciones "Tienen la verdad de la Idea, en terminología hegeliana" que sostiene el autor de Carácter de la Literatura del Perú Independiente ${ }^{6} \mathrm{y}$ "Palma fue el caso de un literato puro. Hizo arte por el arte, sin ninguna mezcla de propósito ideológico, sin ninguna postura de conductor" según anota Víctor Andrés Belaúnde?.

Tanto el concepto de Riva Agüero como el de Belaúnde son la expresión de una filosofía idealista, propia de las clases dominantes para justificar su destino histórico. Rosental dice al respecto: "Por sus raíces sociales, el idealismo, en oposición al materialismo, suele aparecer como concepción del mundo de las capas y clases conservadoras y reaccionarias no interesadas en que se refleje con fidelidad el ser ni en que se desarrollen

6 Ibíd. pp. 186-187.

7 Belaúnde, Víctor Andrés. La Realidad Nacional. (En torno al libro de Mariátegui). Ed. "Le Livre Libre", París, 1931, p. 301. 
las fuerzas productivas y se reestructuren radicalmente las relaciones sociales." ${ }^{\prime}$

Mas, ni las Tradiciones Peruanas tienen la verdad de la idea, ni Palma fue un literato puro. Todo lo contrario. En las Tradiciones existe un profundo sentido desmitificador de la realidad peruana. Tal es lo que podemos observar en esa suerte de acotaciones de crítica social y política que Palma inserta en tradiciones como Los Caballeros de la Capa donde dice: "Caídos y levantados, hartos y hambrientos, eso fue la colonia, y eso ha sido y es la república".

No hay, en nuestra opinión, ningún escritor ni historiador que haya condensado en una frase, como Palma, la realidad de nuestro país; realidad donde las diferencias económicas y sociales entre una minúscula argirocracia o aristocracia de la plata (la expresión es de Palma) y una gran mayoría de desarrapados y hambrientos, son insalvables y abismales.

Las Tradiciones Peruanas, en este sentido, no son ajenas a la constante que José Antonio Portuondo encuentra en la literatura latinoamericana: "Hay una constante en el proceso cultural latinoamericano y es la determinada por el carácter predominante instrumental - Alfonso Reyes diría "ancilar"de la literatura, puesta, la mayor parte de las veces, al servicio de la sociedad." 9

8 Rosental, M. M. Diccionario Filosófico, Ed. Pueblos Unidos, Lima, 1980, p. 301.

9 Portuondo, José Antonio. La Emancipación Literaria de Hispanoamérica, Ed. Casa de las Américas, La Habana, 1975, p. 5. 


\section{Lectura de Manuel González Prada}

En 1879-nuestro año terrible, según acota Luis Alberto Sánchezse inició la guerra con Chile. Entre ese año y 1885, el sacrificio y el heroísmo de unos cuantos no bastó para triunfar; para ello hubiera bastado ser una nación, pero en aquel momento no lo éramos. Manuel González Prada encarna entonces la protesta radical. Sus frases son lapidarias. El Perú —dice-es un organismo enfermo: donde se aplica el dedo brota pus. Hay que destruir l'ancien régimen para hacer una transformación total; para dar paso a las ideas y los hombres nuevos. Los viejos a la tumba, los jóvenes a la obra, sentencia la vehemencia y la pasión del iconoclasta.

La guerra con Chile es el detonante de la nueva voz de la literatura y el pensamiento peruanos. "La mano brutal de Chile —dice González Prada en su Discurso en el Politeama — despedazó nuestra carne y machacó nuestros huesos; pero los verdaderos vencedores, las armas del enemigo, fueron nuestra ignorancia y nuestro espíritu de servidumbre"10. González Prada denuncia las verdaderas causas de nuestra derrota. La clase dominante es la responsable. Porque ha vivido en una terra incógnita, porque el Perú era su encomienda y no su nación. Las clases gobernantes nunca fueron peruanas si al Perú lo entendemos como una totalidad y no como un territorio donde unos pocos son los amos, y los más los parias y desposeídos. Por eso González Prada dice también en su Discurso en el Politeama: "Hablo, señores, de la libertad para todos, y principalmente para los más desvalidos. No forman el verdadero Perú las agrupaciones de criollos y extranjeros que habitan la faja de tierra situada entre el Pacífico y los Andes; la nación está formada por las muchedumbres de indios diseminadas en la banda oriental de la Cordillera. Trecientos años hace que el indio rastrea en las

10 González Prada, Manuel. Pájinas Libres, Ed. Mercurio, $3^{\text {a }}$ Ed., Lima, 1978, p. 9. 
capas inferiores de la civilización (...) enseñadle siquiera a leer y escribir, y veréis si en un cuarto de siglo se levanta o no a la dignidad del hombre."11

En este contexto de repulsa al pasado, se va gestando un conflicto generacional en el movimiento intelectual y literario de la época. Los jóvenes rodean al autor de Pájinas Libres y así se funda el Círculo Literario. Al ser electo su presidente, dice González Prada: "Me veo, desde hoy, a la cabeza de una agrupación destinada a convertirse en el partido radical de nuestra literatura". Un año después evaluando la labor cumplida, señala en su Discurso en el Teatro Olimpo (1887): "El Círculo Literario, la pacifica sociedad de poetas y soñadores tiende a convertirse en un centro militante y propagandista. ¿De dónde nacen los impulsos del radicalismo en literatura? Aquí llegan ráfagas de los huracanes que azotan a las capitales europeas, repercuten voces de la Francia incrédula y republicana. Hay aquí una juventud que lucha abiertamente por destrozar los vínculos que nos unen al pasado; una juventud que desea matar con muerte violenta lo que parece destinado a sucumbir con agonía importunamente larga; una juventud, en fin, que se impacienta por suprimir obstáculos y abrirse camino para enarbolar la bandera roja en los desmantelados torreones de la literatura nacional."12

El radicalismo de Manuel González Prada reclama, pues, un cambio total. En lo social y en la literatura. Y en el mismo discurso del Teatro Olimpo, acuña una frase que adquirirá una pronta y duradera fortuna como lectura de las Tradiciones Peruanas: "Cultivamos — dice- una literatura de transición, vacilaciones, tanteos y luces crepusculares. De la poesía van

11 Ibíd. pp. 11-12.

12 Ibíd. p. 57. 
desapareciendo las descoloridas imitaciones de Bécquer; pero en la prosa reina siempre la mala tradición, ese monstruo engendrado por las falsificaciones agridulcetes de la historia y la caricatura microscópica de la novela."13

Respecto a esta apreciación de las Tradiciones Peruanas y al distanciamiento entre Ricardo Palma y Manuel González Prada se han dado algunas explicaciones. Unas advierten la razón del antagonismo en un problema de carácter generacional; otras — como las que sostienen Haya y Mariátegui - consideran la recuperación de la obra de Palma por críticos como Riva Agüero que identificaron la tradición con una literatura colonialista. También se han señalado como otras explicaciones, el juego maniqueo del civilismo que enfrentó a Palma con González Prada; y, finalmente, el radicalismo de González Prada frente a un país en escombros, radicalismo que no contribuyó a distinguir la trascendencia literaria y socio-cultural de las Tradiciones Peruanas.

Estas explicaciones, sin embargo, no bastan para entender el problema en sí. En la sentencia de González Prada - punto de partida de una lectura peyorativa de las Tradiciones- está presente, ante todo, una concepción de los géneros literarios.

En efecto, el problema nodal respecto a las tradiciones está en aceptar o no su originalidad como género literario. Desde González Prada hasta ahora, la crítica ha adoptado una u otra posición. Para unos - entre los que hay que contar a González Prada y sus seguidores - la tradición no vendría a ser sino un pastiche, un género menor; para otros, en cambio, "La tradición creada por Palma — como dice Raúl Porras Barrenechea- es un género literario propio e inconfundible que no se amolda ni cabe en los géneros conocidos. Es un producto genuino,

13 Ibíd. p. 59. 
limeño y criollo. No es historia, novela, ni cuento, ni leyenda romántica."14

La historia de los géneros literarios, como se sabe, ha transcurrido en base a dos concepciones: una, suprahistórica; y otra, dialéctica. La primera tiene su paradigma en la estética del clasicismo francés; concibe al género literario como un mundo cerrado, fijo e inmutable; considera a los géneros greco-latinos como los modelos ideales; y establece la división de los géneros en mayores y menores.

La concepción dialéctica -que aparece con el barroco y el romanticismo- admite, en cambio, la posibilidad de la creación de nuevos géneros y no reconoce modelos ideales. Su estética podría resumirse en la frase de José Martí: "Cada estado social trae su literatura".

En la discusión y planteamientos respecto a la tradición como género literario subsisten, de uno u otro modo, estas dos concepciones. Los críticos que afirman o niegan la originalidad de la tradición como género literario, que la categorizan como género menor o la consideran como una creación autónoma, evidencian -quizá con mayores o menores fundamentossu identificación con una de las dos posiciones señaladas. Nosotros, por nuestro lado, pensamos que la tradición no es un género ni mayor ni menor, sino más bien una creación de prosapia y linaje latinoamericanos, y, como tal, no hay por qué compararla con otros géneros literarios de raigambres y destino diferentes a los nuestros. En este sentido, nos parece muy a propósito la afirmación de Eduardo Galeano: "No compartimos

14 Palma, Ricardo. Tradiciones Peruanas, Selección y Reseña de la Historia Cultural del Perú por Raúl Porras Barrenechea, Colección Panamericana, Ed. W. M. Jackson, 3ª. Ed., Buenos Aires, 1957, p. XLIV. 
la sacralización de la literatura como institución congelada de la cultura burguesa. La crónica y el reportaje de tirajes masivos, los guiones para radio, cine y televisión y la canción popular no siempre son géneros "menores" como creen algunos marqueses del discurso literario especializado que los miran por encima del hombro." 15

\section{Lectura de José Carlos Mariátegui y Víctor Raúl Haya de la Torre}

Casi medio siglo después, el año 1925, un joven político e intelectual, Víctor Raúl Haya de la Torre, aporta una nueva lectura de la obra de Palma. Lectura, esta vez, más lúcida y penetrante; hecha, por otro lado, con una nueva ideología política y social. En una carta dirigida a la revista Sagitario, y publicada luego en sus Obras Completas bajo el título de La Nueva y la Vieja Generación de Intelectuales en el Perú, dice Haya de la Torre: "Personalmente, creo que Palma fue tradicionista pero no un tradicionalista. Creo que Palma hundió la pluma en el pasado para luego blandirlo en alto y reírse de él. Ninguna institución u hombre de la Colonia y aún de la República escapó a la mordedura tantas veces certera de la ironía, el sarcasmo y siempre el ridículo de la jocosa crítica de Palma. (...) Si Palma había puesto en ridículo el pasado peruano, González Prada lo atacaba despiadadamente. Implacable como los viejos profetas, Prada ha sido el único hombre del Perú en el siglo XIX que ha dicho la verdad desnuda. (...) Pero entre Palma que se burlaba y Prada que azotaba, los hijos de ese pasado y de aquellas castas doblemente zaheridas, prefirieron el alfilerazo al látigo."16

15 Galeano, Eduardo. Sociedad y Literatura en América Latina en: La imagen, Suplemento Dominical de La Prensa Lima, 3 de octubre de 1976.

16 Haya de la Torre, Víctor Raúl. Obras Completas Tomo I, Ed. Juan Mejía Baca, 3a , Lima, 1984, p. 95. 
Haya de la Torre es, en este sentido, uno de los primeros en advertir y rescatar el aspecto crítico de las Tradiciones Peruanas. "No soy -dice- literato ni crítico. Diré con ese gran poeta, el indio César Vallejo, que más que la literatura me interesa lo vital." 17 Y lo vital, el sentido de lo vital, lo percibe Haya de la Torre en escritores como Palma y González Prada, en los jóvenes como Mariátegui, Basadre, Porras, Vallejo, Eguren, etc.; y no en los conservadores y envejecidos intelectuales de la generación retórica de Riva Agüero y Belaúnde. La polémica en torno al carácter de la literatura peruana va adquiriendo, de este modo, contornos ideológicos bien claros. De un lado se sitúan, José de la Riva Agüero y Víctor Andrés Belaúnde, representantes del antiguo orden; y del otro, Víctor Raúl Haya de la Torre y José Carlos Mariátegui que, bien pronto, irrumpirá en la escena con su magistral Siete Ensayos de Interpretación de la Realidad Peruana.

Un año más tarde, desde Londres, Haya de la Torre le escribe a Mariátegui, a propósito de la aparición del primer número de Amauta. En su carta, el fundador del Aprismo desarrolla una serie de ideas que revisten singular importancia. En primer lugar, muestra los mecanismos del dominio intelectual y político de la clase dominante; destaca, luego, el paralelismo entre González Prada y Palma, ambos, a su manera, escritores críticos de su sociedad, pero enfrentados y separados por la insidia del civilismo; y finalmente, expone su interpretación "política" de la literatura: "Mi punto de vista -dice- es que en la literatura hay un valor político que me parece que es la garantía de perennidad de las obras maestras." 18 Y desde esta perspectiva, respecto al autor de las Tradiciones Peruanas dice: “ (...) he encontrado el valor o el más alto prestigio de la obra de Palma como una crítica formidable a la época colonial, al

17 Ibíd. p. 100.

18 Ibíd. p. 120. 
pasado todo, que la interpretación civilista de la literatura del Perú independiente torció, por saberse parte de ese pasado, interpretándolo como un manriquismo negativo y burgués." ${ }^{19}$

Aceptable o no la interpretación "política" de la literatura según Haya de la Torre, lo cierto es que, como dice José Carlos Mariátegui: "Pertenece al mismo Haya una precisa y, a mi juicio, oportuna e inteligente mise aupoint sobre el sentido histórico y político de las Tradiciones." 20

En el año 1928 aparece Siete Ensayos de Interpretación de la Realidad Peruana de José Carlos Mariátegui. El último de estos ensayos trata sobre la literatura peruana, bajo el título de El Proceso de la Literatura. Una de las ideas centrales del pensamiento de Mariátegui respecto a la interpretación de la literatura está en su manera de entender la crítica: "Para una interpretación profunda del espíritu de una literatura, la mera erudición literaria no es suficiente. Sirven más la sensibilidad política y la clarividencia histórica. El crítico profesional considera la literatura en sí misma. No percibe sus relaciones con la política, la economía, la vida en su totalidad. De suerte que su investigación no llega al fondo, a la esencia de los fenómenos literarios (...)."21

Y en Mariátegui se unen, precisamente, la sensibilidad política y la clarividencia histórica, pero también una gran sensibilidad literaria. Al respecto dice Antonio Melis: "Es Mariátegui quien escribe uno de los primeros ensayos latinoamericanos sobre Joyce, quien sigue con agudeza excepcional la obra de Rilke, Yesenin, de Bretón, de Valle Inclán, etc. Las páginas literarias

19 Ibíd. p. 123.

20 Mariátegui, José Carlos. Siete Ensayos de Interpretación de la Realidad Peruana, Ed. Amauta, 43a . Ed., Lima, 1980, p. 247.

21 Loc. Cit. 
de Amauta están abiertas sobre todo a las voces más nuevas de la literatura nacional y mundial. Pero siempre conserva su libertad de juicio con respecto a los varios movimientos de vanguardia." 22

Pero a estas cualidades habría que añadirle quizá otra más importante: la formación ideológica de Mariátegui en la filosofía del marxismo, pero no en un marxismo petrificado y dogmático sino más bien dialéctico y vivificador, tal como él mismo lo entendía en su Defensa del Marxismo: "Lenin nos prueba, en la política práctica, con el testimonio irrecusable de una revolución, que el marxismo es el único medio de proseguir y superar a Marx.”

Todo ello le da a la visión de Mariátegui una concepción más profunda del proceso de la literatura en el Perú. "Riva Agüero -dice- enjuició la literatura con evidente criterio "civilista”. (...) El espíritu de casta de los "encomenderos" coloniales, inspira sus esenciales proposiciones críticas que casi invariablemente se resuelven en españolismo, colonialismo, aristocratismo. Riva Agüero no prescinde de sus preocupaciones políticas y sociales, sino en la medida en que juzga la literatura con normas de preceptista, de académico, de erudito; y entonces su prescindencia es solo aparente porque, sin duda, nunca se mueve más ordenadamente su espíritu dentro de la órbita escolástica y conservadora". Y luego añade: "Por mi parte a su inconfesa parcialidad "civilista" o colonialista enfrento mi explícita parcialidad revolucionaria o socialista." 23

Los teóricos del arte por el arte, de la literatura pura, han sostenido siempre la tesis del apoliticismo en el arte. iComo si esto fuese

22 Mariátegui, José Carlos. Crítica Literaria, Ensayo Preliminar de Antonio Melis. Ed. Jorge Álvarez Buenos Aires, 1969, p. 44.

23 Mariátegui, José Carlos. Siete Ensayos..., Ob. Cit., pp. 231-232. 
posible! Víctor Andrés Belaúnde escribe precisamente su libro La Realidad Nacional (En torno al último libro de Mariátegui), que aparece en París el año 1931, para refutar las tesis de Mariátegui. Pero lo hace sin comprender el verdadero pensamiento de Mariátegui —uno de los pensamientos más libres de la América Latina-y dice entonces que su separación del autor de los Siete Ensayos se debe a la ideología materialista y cerrada a la que este se adhirió en los últimos años ${ }^{24}$.

Luego añade que Mariátegui comete el error de contemplar y apreciar la producción literaria con un criterio político. Pero él mismo, más adelante, escribe: "Dentro de la mentalidad católica, que es la única en que se estructura la independencia y jerarquía de los diversos aspectos de la realidad, han vivido los artistas más libres: Dante, Cervantes, Claudel.”25

¿Y esto no es acaso plantear un punto de vista político de la literatura? ¿No ha sido acaso, y no es hoy mismo, cierta mentalidad católica una expresión política de las fuerzas conservadoras y reaccionarías de la clase dominante?

Mariátegui establece un deslinde claro respecto a la naturaleza de toda crítica cuando escribe: "Mi crítica renuncia a ser imparcial, o agnóstica, si la verdadera crítica puede serlo. Toda crítica obedece a preocupaciones de filósofo, de político o de moralista"26. O dicho de otro modo, toda crítica es la expresión de una ideología. Por ello es explicable que Belaúnde sostenga que "Palma fue el caso de un literato puro. Hizo arte por el arte, sin ninguna mezcla de propósito ideológico, sin ninguna postura de maestro conductor." ${ }^{27}$

24 Belaúnde, Víctor Andrés. Ob. Cit., p. 136.

25 Ibíd. p. 138.

26 Mariátegui, José Carlos. Siete Ensayos..., Ob. Cit. p.230.

27 Belaúnde, Víctor Andrés. Ob. Cit., p. 159. 
Mariátegui, en cambio, desde su perspectiva, advierte en Palma a un autor inmerso en las preocupaciones políticas y sociales como González Prada. Por eso mismo dice: "Una historia de la literatura peruana que tenga en cuenta las raíces sociales y políticas de esta, cancelará la convención contra la cual hoy solo una vanguardia protesta. Se verá entonces que Palma está menos lejos de Gonzáles Prada, de lo que hasta ahora parece."28

Edith Palma, por su parte, resume los puntos de vista de Riva Agüero, Haya de la Torre y Mariátegui en los siguientes términos: "Otro aspecto del infortunio — que no niega la ventura de las Tradiciones - estaría bien mirarlo en la interpretación oportunista que merecieron durante muchos años, hasta el punto de que el autor pasaba, por arte de birlibirloque, de su entrañable escenario democrático, camuflada adrede su sonrisa volteriana, al tabladillo de la literatura cortesana, auspiciada por el civilismo claudicante y converso. Débase reconocer esta revalorización social de la obra de Palma a Víctor Raúl Haya de la Torre. El mismo punto de vista del escritor político lo adopta, más tarde, José Carlos Mariátegui, al glosarlo agudamente en su ensayo sobre El Proceso de la Literatura. Ambos escritores coinciden, pues, en rescatar la figura de Palma, mejor dicho, su obra." ${ }^{29}$ Y respecto a esa vinculación que advierte Mariátegui entre Palma y Gonzáles Prada, Edith Palma agrega: "Sí el género de las Tradiciones no se compadece con el carácter y asunto de Páginas Libres, en cambio existe una correspondencia subterránea entre la intención ideológica de estos y el espíritu artístico de aquellos. Lo que las vincula por encima de interesadas interpretaciones fariseas es la actitud ante la vida y el mundo. Ambos, cada

28 Mariátegui, José Carlos. Siete Ensayos..., Ob. Cit., pp. 247-248.

29 Palma, Ricardo. Tradiciones Peruanas Completas, Prólogo de Edith Palma, Ed. Aguilar, Madrid, p. XXV. 
cual a su manera y rumbo, comprueban los mismos males y las mismas lacras."30

Corresponde, pues, a los dos mayores ideólogos y políticos del Perú contemporáneo - Haya y Mariátegui - el mérito de habernos dado hasta ahora la más lúcida interpretación o lectura de Palma.

30 Loc. Cit. 